\title{
Relation between knowledge, foot self-care and health status for diabetic foot high-risk patients
}

\author{
1Noura Mahfouz, 2Taghreed TalatShakweer, 3Marwa Abd-Elaziz
}

1M.S. Assistant Lecturer of adult health nursing department, faculty of Nursing, BaniSwiefUniversity, Bani-Swief, Egypt

2PhD, Assistant Professor of adult health nursing department, faculty of Nursing, HelwanUniversity, AinHelwan, Cairo, Egypt

$3 P h D$, lecturer of adult health nursing \& Focal point of international relation, faculty of nursing, Helwan university, AinHelwan, Cairo, Egypt

\begin{abstract}
Diabetes mellitus (DM) is a public health problem andis the leading cause of hospital admission, amputation and mortality in diabetic patients. Aim of the study: This study was conducted to assess relation betweenknowledge, foot self-care and health status for diabetic foot high-risk patients. Research design: A descriptive exploratory design was utilized was used in this study. Setting: the study was conducted in diabetic foot outpatient clinic in Beni-Suef university hospital at Beni-Suef city Egypt. Subjects: A purposive sample of 60 patients admitted in diabetic foot outpatient clinic. Data Collection Tools: Tools of the study consist of four tools, tool (1) Lower limb assessment sheet for diabetic patients (2) Patient's interview questionnaire sheet (3) Diabetic foot observational checklist (4) health status assessment sheet. Results: $(61.2 \%)$ of studied patients had satisfactory level of total knowledge regarding diabetes mellitus. (49.0\%) of them had unsatisfactory self-care of the foot. The study results revealed, that there is statically significant relation between patients' health status and knowledge and no statically significant relation between patients' health status and diabetic foot self-care. Conclusion: This study concluded that there is statically significant relation between patients' health status and knowledge and there is no statically significant relation between patients' health status and diabetic foot selfcare.Recommendation:Diabetic foot programs for high-risk patients, health status recommend to be conducted in diabetic foot outpatient clinics by specialized well-trained nurses.
\end{abstract}

Key wards: Diabetic Foot-Knowledge-Health Status-Foot Care. 


\section{Introduction}

Diabetes mellitus (DM) is a public health problem and the leading cause of morbidity and mortality worldwide. Global diabetes incidence is increasing rapidly lead to increase in its complications among diabetic patients. One important complication of DM is the foot problems; these complications constitute an increasing public health problem and leading cause of hospital admission, amputation and mortality in diabetic patients (Tolossa et al., 2020).

$$
\text { Diabetic foot imposes a }
$$

substantial burden on the economy in the form of increased medical costs and indirect costs from work-related absenteeism, reduced productivity at work and at home, reduced labor force participation from chronic disability and premature mortality. In addition to the economic burden that has been quantified, diabetes imposes high intangible costs on society in terms of reduced quality of life and pain and suffering of people with diabetes, their families, and friends (Center for Disease Control \& prevention, 2011).

Risk factors for foot problems in patients with DM include age $\geq 65$ years, obesity, hypertension, nephropathy, lipid disorders, cardiovascular disease, other DM comorbidities (e.g., neuropathy, peripheral vascular disease, previous foot ulcer, vascular surgery, charcot foot, impaired wound healing), foot deformity (e.g., hallux rigidus, hammer toes) and infection. Persons with DM are prone to infections due to diminished immune system functions due to lower phagocytosis and bactericidal ability, peripheral vascular disease and neuropathy, poor foot hygiene/care, smoking cigarettes, edema, male gender, hyperglycemia and poor glycemic control ( $\mathrm{HbA} 1 \mathrm{c}>9 \%)$ (National Institute for Health Care \& Excellence, 2016).

The diabetic foot care program implemented is a comprehensive approach to maintaining the health of diabetic patients' feet in order to reduce the lower limb amputation rate, thereby dramatically reducing the cost to patients, society, and the health care system. Knowledgeable and consistent care can help patients avoid the potential problems that may lead to amputation. The patients' continued walking ability and quality of life depend on close inspection, proper footwear, a few specific "do's and don'ts", and the commitment of the medical care team (Fitzgerald \& Keyes, 2016).

\section{Aim of the Study:}

This study aims to assess relation between knowledge, foot self-care and health status for diabetic foot high-risk patients.

\section{Research Questions:}

What is the relation between knowledge, foot self-care and health status for diabetic foot high-risk patients?

Research design: A descriptive exploratory designwas used in this study.Subjects: A Purposive sample of 60 patients from both genders, with different ages and educational levels were selected for this study.Setting: This study was carried out at diabetic foot outpatient clinic in Beni-Suef university hospital.

\section{Inclusion and Exclusion criteria:}

The inclusion criteria of the current study include diabetic patient type I or type II.Past or recent history of diabetic foot ulcer, past or recent history of foot amputation, absent pedal pulses in one or both feet, positive monofilament test in one or both feet and 
Relation between knowledge, foot etc...

free from psychotic and mental disorders.

\section{Tools for data Collection:}

Data were collected using the following tools: Tool (I): Patients interview questionnaire sheet: This tool developed by the researcher based on review of relevant recent literatures and including three parts: Part IDemographic data assessment tool: It was developed by the researcher and written in Arabic language.It aimed to assess the patients 'demographic characteristics including age, gender, level of education, marital status, occupation and residence. Part IIMedical data assessment tool:It developed by the researcher based on related literature. It was used to assess and collect medical data about patients' history include present,past and family health history.

Part III -Patients knowledge assessment: It developed by the researcher based on related literature. It was used to assess patient's knowledge regarding diabetes mellitus.Tool (II): Lower limb assessment sheet for diabetic patient: This tool was adopted from Sibbald, (2012). It was aimed to assess high risk patients as past, recent history of diabetic foot ulcer, past or recent history of foot amputation, absent pedal pulses in one or both feet, positive monofilament test in one or both feet.

Tool (III): Diabetic foot selfcare observational Checklist: It developed by the researcher based on related literature and it filled by the researcher to assess foot self-care for foot.Tool (V): Health status assessment sheet: It was developed by the researcher based on literaturereview to assess patients' health status as fasting blood sugar level, postprandial blood sugar level, blood pressure and HbA1C.

\section{Scoring system:}

The total score of lower limb assessment sheet for diabetic patients' was10 grades. a) Positive ScreenResults when there are one or more "Yes" responses. These individuals are at increased risk of a foot ulcer and/or infection. b) Negative screen- Results when there are all "No" responses. $\geq$ $60 \%$ of correct knowledge was satisfactory level of knowledge when the total grades were $\geq 12$ grades. $<60 \%$ of incorrect knowledge was unsatisfactory level of knowledge when the total grades were $<12$ grades. $\geq 60 \%$ of correct practice was satisfactory level of foot self -care for foot when the total grades were $\geq 8$ grades. $<60 \%$ of incorrect practice was unsatisfactory level of foot self- care for foot when the total grades were $<8$ grades.

Field Work Procedure:

Preparation phase:A Purposive sample of 60 patients from both genders, with different ages and educational levels were selected for this study. Implementation phase:An official permission for conducting the study was obtained from the director ofBeni-Suef university hospital. Development of tool I, II, III\&V after reviewing recent relevant literatures. Data collection was done 2 day/weak by the researcher, two times per day at the morning shift.

\section{Ethical Considerations:}

Ethical approval was obtained from the scientific ethical committee of Helwan University. In addition, written informed consent was obtained from each participant prior to data collection. The participants assured that anonymity and confidentiality would be guaranteed and the right to withdraw from the study at any time. Ethics, values, culture and beliefs were respected. 


\section{Statistical Design:}

The collected data were organized, categorized, tabulated, and statistically analyzed using the statistical package for social science (SPSS) version (20). Data were presented in tables and graphs. The statistical analysis included; percentage (\%), the arithmetic mean $\overline{\mathrm{X}}$ ), standard deviation (SD), chisquare (X2), and Pearson correlation (r).

\section{Results:}

\section{Table (1):Percentage distribution of demographic characteristics of the studied} patients $(\mathrm{N}=60)$.

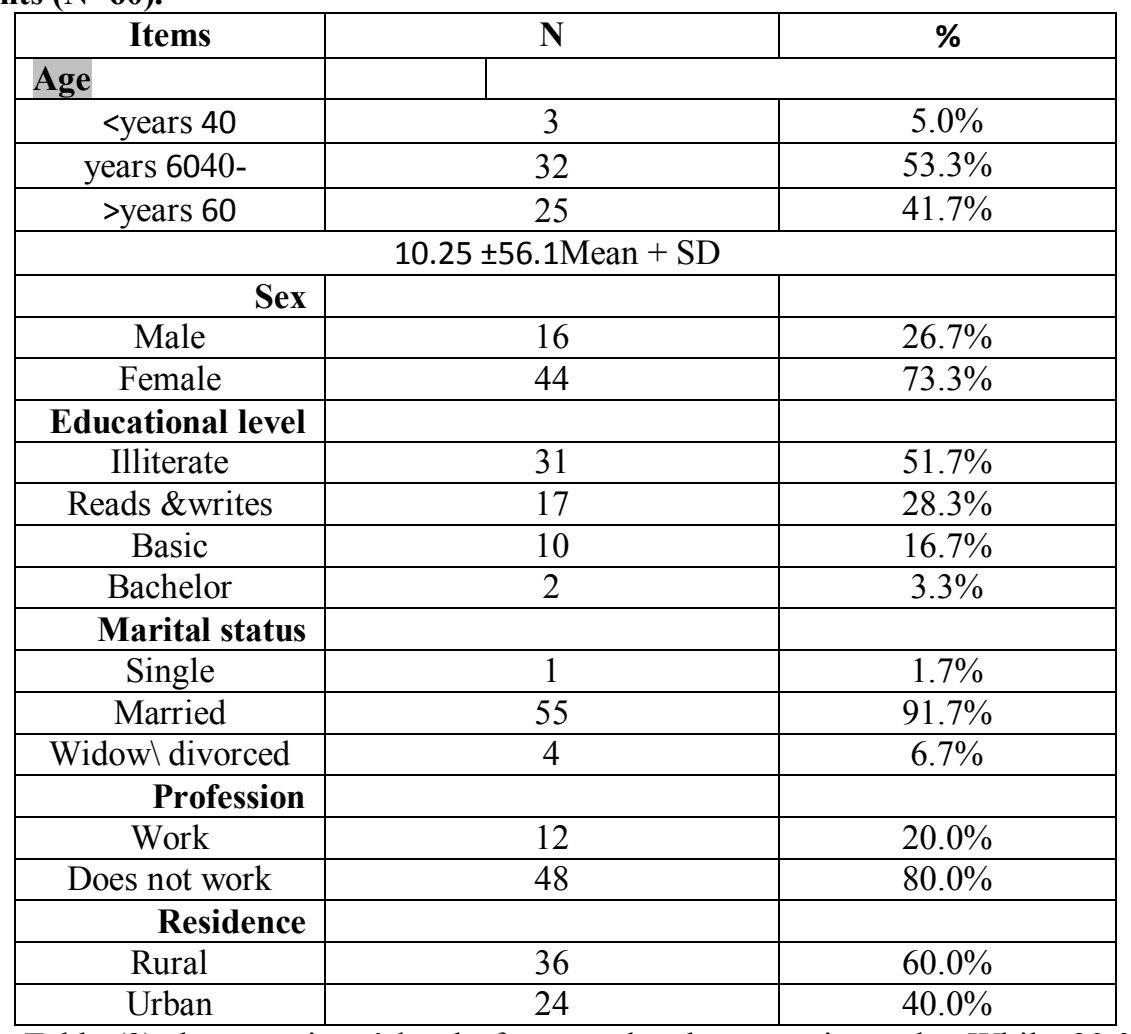

Table (2) shows patients' level of knowledge about diabetic mellitus. The results reveal that, $91.7 \%$ and $90.0 \%$ of them had satisfactory level of knowledge regarding treatment should be taken regularly to avoid complications and periodic examination of the foot should

\section{- Demographic characteristics of} the studied patients.

Table (1) clarifies, the mean age of the studied patients was $(56.1 \pm 10.25)$ and $73.3 \%$ of them were females. Also $51.7 \%$ were illiterate, Moreover.91.7\% of them were married and $80.0 \%$ were not working. Lastly concerning residence, $60.0 \%$ of them resided in rural area as illustrated in tables (1). 
Table (2): Distribution of patients' level of knowledge regarding diabetes mellitus $(\mathbf{N}=60)$.

\begin{tabular}{|l|c|c|}
\hline Patients' knowledge regarding diabetes mellitus & $\mathbf{N}$ & $\mathbf{\%}$ \\
\hline 1-Definition of the disease & 18 & $30.0 \%$ \\
\hline 2 - the age group exposed & 33 & $55.0 \%$ \\
\hline 3. Normal level of fasting blood glucose & 22 & $36.7 \%$ \\
\hline 4- Causes of the disease. & 18 & $30.0 \%$ \\
\hline 5- The factors lead to high blood sugar? & 14 & $23.3 \%$ \\
\hline 6- The signs and symptoms of the disease: & 43 & $71.7 \%$ \\
\hline 7- Insulin injections should be taken: & 45 & $75.0 \%$ \\
\hline 8- Treatment options & 51 & $85.0 \%$ \\
\hline 9- To avoid recurrence of diabetic foot problems & 43 & $71.7 \%$ \\
\hline 10- Factors lead to amputation of diabetic foot & 17 & $28.3 \%$ \\
\hline $\begin{array}{l}\text { 11-Treatment should be taken regularly to avoid complications of } \\
\text { diabetes. }\end{array}$ & 55 & $91.7 \%$ \\
\hline $\begin{array}{l}\text { 12-Individual health awareness of diabetes complications may } \\
\text { reduce the incidence of amputation for the foot }\end{array}$ & 53 & $88.3 \%$ \\
\hline 13-Symptoms of hypoglycemia & 52 & $86.7 \%$ \\
\hline $\begin{array}{l}\text { 14-Diabetes complications are limited to diabetic foot amputation } \\
\text { only. }\end{array}$ & 26 & $43.3 \%$ \\
\hline $\begin{array}{l}\text { 15-Kidney disease is a health problem that occurs from } \\
\text { complications of diabetes. }\end{array}$ & 31 & $51.7 \%$ \\
\hline $\begin{array}{l}\text { 16-Lung disease is a health problem that results from diabetes } \\
\text { complications. }\end{array}$ & 22 & $36.7 \%$ \\
\hline $\begin{array}{l}\text { 17-Loss of pain and unpleasant odors in the foot indicate a } \\
\text { problem with the foot. }\end{array}$ & 50 & $83.3 \%$ \\
\hline $\begin{array}{l}\text { 18-Severe inflammation of the foot tissue (incurable) and eat in the } \\
\text { bone of the symptoms that lead to amputation of the diabetic foot. }\end{array}$ & 38 & $63.3 \%$ \\
\hline $\begin{array}{l}\text { 19-Periodic examination of the foot should be done continuously. } \\
\text { 20-Neglecting routine foot examination may lead to foot problems. }\end{array}$ & 54 & $90.0 \%$ \\
\hline & 734 & $61.7 \%$ \\
\hline
\end{tabular}

Table (3) showspatients' self-care of the foot, the results reveals that $96.7 \%$ $\& 93.3 \%$ of them had satisfactory selfcareregarding choose shoes with low heels, and wash and dry foot every day. While $13.3 \%$ \&1.7\%, of them had, unsatisfactory self-care regarding and check for foreign objects in shoes before wearing them and apply a good skin lotion every day on foot heels and soles. Finally, $49.0 \%$ of them had unsatisfactory self-care of foot totally. 
Table (3):Distribution of diabetic foot observational checklist for care of foot among the study group $(\mathrm{N}=60)$.

\begin{tabular}{|c|c|c|}
\hline Self-care of foot & No & $\%$ \\
\hline $\begin{array}{l}\text { Check foot every day for cuts, cracks, bruises, } \\
\text { blisters, sores, infections or unusual markings. }\end{array}$ & 22 & $36.7 \%$ \\
\hline $\begin{array}{l}\text { - Use a mirror to see the bottom of the foot if cannot } \\
\text { lift up. }\end{array}$ & 9 & $15.0 \%$ \\
\hline - Color & 15 & $25.0 \%$ \\
\hline - $\quad$ Swelling & 31 & $51.7 \%$ \\
\hline - Warmth & 15 & $25.0 \%$ \\
\hline $\begin{array}{l}\text { - Clean a cut or scratch with a mild soap and water } \\
\text { and cover with a dry dressing for sensitive skin. }\end{array}$ & 55 & $91.7 \%$ \\
\hline - $\quad$ Trim nails straight across. & 45 & $75.0 \%$ \\
\hline $\begin{array}{l}\text { - Check the water temperature with wrist or a } \\
\text { thermometer (not by using foot), before getting into } \\
\text { a bath }\end{array}$ & 34 & $56.7 \%$ \\
\hline $\begin{array}{l}\text { - Wash and dry foot every day, especially between } \\
\text { the toes. }\end{array}$ & 56 & $93.3 \%$ \\
\hline - Dry foot completely. & 12 & $20.0 \%$ \\
\hline $\begin{array}{l}\text { - Apply a good skin lotion every day on foot heels } \\
\text { and soles. }\end{array}$ & 1 & $1.7 \%$ \\
\hline - $\quad$ Always wear a good supportive shoe. & 44 & $73.3 \%$ \\
\hline $\begin{array}{l}\text { - Check for foreign objects in shoes before wearing } \\
\text { them. }\end{array}$ & 8 & $13.3 \%$ \\
\hline - $\quad$ Choose shoes with low heels (under $5 \mathrm{~cm}$ high). & 58 & $96.7 \%$ \\
\hline - $\quad$ Avoid going barefoot outside or indoors & 36 & $60.0 \%$ \\
\hline Total score & 441 & $49.0 \%$ \\
\hline
\end{tabular}

There is statically significant relation between patients' health status and knowledge regarding diabetes statically significant relation between patients' health status and diabetic foot mellitus as $\mathrm{P}<0.05$., but there is no observational check list as $\mathrm{P}>0.05$.

Table (4): Relation between patients 'knowledge, diabetic foot observational check list and health status.

\begin{tabular}{|l|c|c|c|c|c|}
\hline \multicolumn{1}{|c|}{$\begin{array}{c}\text { Patients' health } \\
\text { status }\end{array}$} & \multicolumn{5}{|c|}{ Total Knowledge } \\
\cline { 2 - 5 } & N & \% & SD & T & P value \\
\hline Good & - & - & - & - & - \\
\hline Fair & 6 & $\% 10$ & 13.57 & 3.09 & 0.01286 \\
\hline Poor & 54 & $\% 90$ & 24.04 & \\
\hline $\begin{array}{c}\text { Patients' health } \\
\text { status }\end{array}$ & \multicolumn{5}{|c|}{ Diabetic foot observational check list } \\
\hline Good & - & - & - & - & - \\
\hline Fair & 6 & $\% 10$ & 13.61 & 1.02 & 0.31310 \\
\hline Poor & 54 & $\% 90$ & 13.84 & & \\
\hline
\end{tabular}

Discussion:

The current study is a descriptive study aimed to assess relation between knowledge, foot self-care and health status for diabetic foot high risk patients.

Regarding the studied patients' demographic characteristics, the results 
of the present study revealed that more than half of the studied patients were 4060 years old and around three quadrants of them were female. This result is in accordance with kirkman et al., (2012) who confirmed that older adults with diabetes are substantial risk for foot problem. This may be due to increased risk of chronic disease related foot problem such as diabetes among females at the same age group in Egypt.

Regarding to educational level, this study result revealed that more than half of the studied patients had Illiterate. This finding is in accordance with that of a recent study of Soomro, Khan, Ahmed \&Minhas, (2013), they assessed and found that low educational level has been a major significant predictor for foot problem among diabetic patients. This result may due to lack of information about importance of foot self-care and lack of educational programs for those patients.

In the current study, the result showed that the majority of studiedpatients were married. This result is supported bySakin\& Alay (2021), who assessed patients with diabetes and reported that about most of study sample were married. This may due to the most of the studied patients aged from forty to sixty or more years old. Also could be due to life stressors and lack of self-care time of married patients.

Concerning working status, this study finding revealed that more than three quadrantsof studied patients investigated in this study were not working (unemployed \&homemakers). This result is consistent with Srinivasan et al., (2017), they assessed patients and revealed that more than of the study group did not work and lower education. This could be due to more than one third of studied patients were aged more than sixty years old (Retirement age).

As regards, residence of the studied patients, this study findings indicated that around two thirds of them were from rural areas. This result is in agreement with 1-Khawaga\& AbdelWahab, (2015), they reported that most of patients included in study group are residing in urban areas. This may be due to not availability of health services in rural areas through health insurance hospitals in the governorate of Beni-suef town.

Regarding patients' level of knowledge about diabetic foot care, the present study reveals that around half of them had unsatisfactory knowledge about diabetic footcare. This result is in agreement with Muhammad et al., (2014)whoshowed that the majority of patients who were admitted for diabetic foot infections had poor knowledge and poor practice of foot care.

Regarding self-care of the foot, the present study revealed that more than one third of them had unsatisfactory level about regular inspections of their feet. This result is in accordance with Apelqvist\&Larsson, (2016), who revealed that the majority of diabetic individuals do not get regular inspections of their feet, adequate shoes or proper foot care. This result may due to lack of information about importance of foot self-care and lack of educational programs.

Regarding relation between patients' health status and patient's knowledge regarding diabetes mellitus. The presented study revealed that there is statistically significant relation between patients' health status and patient's knowledge regarding diabetes mellitus. The finding is in agreement with Forde et al., (2020)who showed that patients 
have good knowledge about their disease which lead to reducing complications and improving their health-related quality of life.

Conclusion:

This study concluded that there is statically significant relation between patients' health status and knowledge and there is no statically significant relation between patients' health status and diabetic foot self-care.

\section{Recommendations:}

Diabetic foot programs for high risk patients' health status recommend to be conducted in diabetic foot outpatient clinics by specialized well trained nurses.

\section{References:}

Apelqv1st $J$ and Larsson, $J$ (2016):

What is the most effective way to reduce 1 ncidence of amputation $1 \mathrm{n}$ the diabetic foot, diabetes metabolism research and review 16,1 .

Centers for D1sease Control and Prevention (2011): National diabetes fact sheet.Retrievedfromhttp://www.cd c.gov/diabetes/pubs/factsheet11.ht $\mathrm{m}$.

El-Khawaga, G., \& Abdel-Wahab, F. (2015). Knowledge, attitudes, practice and compliance of diabetic patients in Dakahlia, Egypt. Euro J Res Med Sci, 3(1).

Fitzgerald, K., \& Keyes, K. (2016).Teaching methods and settings.In S. B. Bastable (Ed.), Essentials of patient education $2^{\text {nd }}$ ed., pp. 379-416.

Forde, H., Wrigley, S., O'Murchadha, L. T., Cusack, L., Casserly, S., Moneley, D., ...\& Smith, D. (2020). Five-year outcomes of patients attending a diabetic foot clinic in a tertiary referral centre. Irish Journal of
Medical Science (1971-), 189(2), 511-515.

Kirkman M, Priscope V, Clark N, Florez H, Hass, L, Jeffery B, Halter J, Huang E, Korytkowski M, Munshi M, Odegrad $P$ \& swift C (2012): Diabetes in older adults: A Consensus 2 Report Journal of the American geriatrics society:2 (4) 1- 15.

Muhammad, Lutfi, Zaraihah, Anuar, Ramdhan, M\&MedOrth (2014): Knowledge and Practice of Diabetic Foot Care in an In Patient Setting at a Tertiary Medical Center, Malaysian Orthopaedic Journal 2014 Vol 8 No 3.

National Institute for Health Care and Excellence. (2016). Diabetic foot problems: Prevention and management (NICE guideline NG19). Retrieved February 26, 2017, from https://www.nice.org.uk/guidance/ ng19/resources/diabetic-footproblems-prevention-andmanagement-1837279828933 (G).

Sakin, A., \& Alay, M. (2021). Factors affecting glycemic control in patients with type 2 diabetes mellitus using oral antidiabetics: A single-center experience. Medicine, 10(1), 4650.Armstrong, D. G., Boulton, A. J., \& Bus, S. A. (2017).Diabetic foot ulcers and their recurrence. New England Journal of Medicine, 376(24), 2367-2375.

Sibbald, R. G., Ostrow, B., Lowe, J., Ayello, E. A., Alavi, A., Botros, M \& Smart, H. (2012). Screening for the high-risk diabetic foot: a 60 -second tool (2012)(C) diabetes. Wound Healing Southern Africa, 5(2), 72-82. 
Soomro, N,. Khan, M,. Ahmed, S. \&MinhasM(2013):

Determinants of lower extremity amputations: a nine situational experience .Journal of the college of physicians and surgeons Pakistan:32(7) : 49 494 Available at http://www.Jcpsp.pk Accessed on: 7-4-2014 . 1:17AM.

Srinivasan, N. K., John, D., Rebekah, G., Kujur, E. S., Paul, P., \& John, S. S. (2017). Diabetes and diabetic retinopathy: knowledge, attitude, practice (KAP) among diabetic patients in a tertiary eye care centre. Journal of clinical and diagnostic research: JCDR, 11(7), NC01.

Tolossa, T., Mengist, B., Mulisa, D., Fetensa, G., Turi, E., \&Abajobir, A. (2020). Prevalence and associated factors of foot ulcer among diabetic patients in Ethiopia: a systematic review and meta-analysis. BMC Public Health, 20(1), 1-14. 